\title{
VARIOUS FACTORS INVOLVED DURING SAFE LAPAROSCOPIC CHOLECYSTECTOMY IN CASES OF EMPYEMA GALL BLADDER
}

\author{
Muhammad Ismail, Nasir Mehmood Watto, Muhammad Qasim Butt, Fareeha Naz* \\ Pak Emirates Military Hospital/National University of Medical Sciences (NUMS) Rawalpindi Pakistan, *Armed Forces Institute of Cardiology/National \\ University of Medical Sciences (NUMS) Rawalpindi Pakistan
}

\begin{abstract}
Objective: To evaluate the various factors involved during the safe cholecystectomy performed by laparoscopic method in cases of empyema of gall bladder operated at Pak Emirates Military Hospital Rawalpindi.

Study Design: Cross-sectional analytical study.

Place and Duration of Study: Pak Emirates Military Hospital, Rawalpindi, from Nov 2017 to Mar 2019.

Methodology: This study was performed on 70 patients undergoing cholecystectomy by laparoscopic method for empyema gall bladder during the study period. Adverse effects after the procedure were assessed in detail at 48 hours, at time of discharge and two weeks after the procedure on all the participants. Demographic profile and other factors were compared in the groups with and without the complications by using the chi-square test and binary logistic regression.

Results: Out of 70 patients included in the final analysis $24(34.3 \%)$ were male and $46(65.7 \%)$ were female. Mean age of patients who underwent laparoscopic surgery for empyema gall bladder in our study was $42.43 \pm 3.161$ years. Bile duct perforation and leakage $6(8.5 \%)$ was the commonest complication among the patients included in our study followed by surgical site infection $5(7.1 \%)$. With binary logistic regression we found that presence of co-morbids and high preoperative C reactive protein had a strong association with presence of complications among the patients undergoing cholecystectomy in our study while age, gender, transfusion during surgery were not linked with the complications during or after the study.

Conclusion: Limited number of patients faced the complications during or after the surgery. Patients with co-morbid medical illnesses and high $\mathrm{C}$ reactive protein before surgery should be screened with caution for the presence of complications after the surgery.
\end{abstract}

Keywords: Bile duct perforation, C-reactive protien, Empyma gall bladder, Laparoscopic cholecystectomy, Surgical site infection.

This is an Open Access article distributed under the terms of the Creative Commons Attribution License (http://creativecommons.org/licenses/by/4.0), which permits unrestricted use, distribution, and reproduction in any medium, provided the original work is properly cited.

\section{INTRODUCTION}

Empyema gall bladder is not an uncommon presentation in the surgical units ${ }^{1}$. As most of our population belongs to the rural areas so they usually present with complicated gall bladder problems instead of acute uncomplicated problems. Empyema gall bladder is also a common surgical problem in other parts of the world ${ }^{1}$. Laparoscopic management has usually been the treatment of choice for empyema gall bladder and practiced in routine. Centers which do not offer laparoscopic facilities, still use open method of surgery for this procedure ${ }^{2}$.

Hepatobiliary surgery has been an evolving specialty in all parts of the world ${ }^{3}$. With the rise of use of interventional gastroenterological methods, burden of biliary tract surgeons has been reduced but still the role of surgical problems and their definitive surgical management cannot be undermined ${ }^{4}$. Still there is no structured training or fellowship program for hepatobiliary surgery in our country and it is the general

Correspondence: Dr Muhammad Ismail, Department of Surgery, Pak Emirates Military Hospital, Rawalpindi Pakistan

Received: 29 Apr 2019; revised received: 10 Aug 2019; accepted: 17 Aug 2019 surgeons who have taken this burden on them ${ }^{5}$. With various modalities available in recent era it is an utmost requirement for the surgeons to have an accurate knowledge of efficacy and untoward effects of all the modalities so that they can give all the options to the patients with complete clarity.

A recent study done on patients undergoing laparoscopic cholecystectomy for empyema concluded that in male gender, elevated WBC count and increased thickness of gall bladder at the time of presentation were associated with presence of complications. They stated that conversion to open method should not be considered as a complication rather it is a measure to avoid the complications ${ }^{6}$. Another study done on military sample and published in Pakistan Armed Forces Medical Journal revealed that around seven percent patients undergoing laparoscopic cholecystectomy had empyema gall bladder and bleeding, and biliary peritonitis were the commonest complications among these patients ${ }^{7}$. A study comprising of experience of a large center of Sindh, southern province of Pakistan regarding laparoscopic management of empyema gall bladder concluded that cholecystectomy can 
be performed by laparoscopic methods but possibility of complications should be kept in mind even by the trained professionals. It also stated that the expertise of surgeon has a vital role in successful surgeries ${ }^{8}$. Another local study also advocated the use of laparoscopic method for the empyema gall bladder cases especially among the patients with less number of other comorbidities. It was overall cost effective and related to more comfort of the patient ${ }^{9}$.

Duty of a good physician is to have an adequate knowledge regarding the risks and benefits of the procedure he is offering to the patient. No form of treatment is free of hazards but essence lies in having knowledge of these hazards and effective communication to the patient. Though laparoscopic method requires specialized facilities and is expensive as compared to the conventional open method ${ }^{10}$, still the postoperative complications, hospital stay and chances of readmission should be taken into account and briefed to the patient in order to find an overall best option for the procedure. We planned this study to evaluate the various factors involved during safe laparoscopic cholecystectomy in cases of empyema gall bladder operated at General Surgery Department, Pak Emirates Military Hospital Rawalpindi.

\section{METHODOLOGY}

This cross sectional analytical study was conducted at the surgical department of Pak Emirates Military Hospital Rawalpindi from November 2017 to March 2019. Sample size was calculated by WHO Sample Size Calculator by study reference ${ }^{7}$. It turned out to be 50 patients or more. Non probability consecutive sampling technique was used to gather the sample. All patients between the age of 18-65 years who underwent laparoscopic management for empyema gall bladder were included in the study. Patients with uncontrolled physical illnesses like DM, HTN, IHD etc were excluded. Patients with a known gallbladder carcinoma or any other solid or hematological malignancy were also not included in this study. Those undergoing redo surgeries were also the part of exclusion criteria in this study.

Ethics committee of Pak emirates military hospital was approached to get the approval for this study and patients fulfilling the above mentioned inclusion and exclusion criteria were included in the study. Routine analgesia and antibiotic cover was given to each patient as per the hospital protocol and condition of the patient. Detailed assessment regarding all the side effects was done immediately after the procedure at 48 hours, at time of discharge and two weeks after the procedure was done on all the participants. Visual analogue score (VAS score) of $>6$ was considered for significant post-operative pain. Wound discharge and infection, bile leakage and perforation, bleeding, collection of fluid, acute kidney injury and readmission in hospital due to primary surgery were the common short term complications which were noted among all the patients undergoing laparoscopic surgery of empyema gall bladder at our hospital in the study period ${ }^{11-13}$. Mean hospital stay was calculated for all the patients. Comorbidities in the study participants included controlled chronic medical illnesses including Diabetes Mellitus, Ischemic Heart Disease, Hypertension etc ${ }^{14,15}$.

All statistical analysis was performed by using the Statistics Package for Social Sciences version 24 (SPSS-24). Frequency and percentages for gender and all the complications recorded during the study were calculated. Mean and standard deviation for age and stay at hospital was also calculated for the study participants. Age, gender, value of $\mathrm{C}$ reactive protein, presence of comorbidities and history of transfusion during the surgery were compared in the groups with and without the complications by using the chi-square test and binary logistic regression. $p$-value $\leq 0.05$ was considered significant.

\section{RESULTS}

A total of 76 patients were initially approached to get them included in the analysis. Two had diagnosis of cancer before the surgery while four were undergoing redo surgeries. Out of 70 patients included in the final analysis $24(34.3 \%)$ were male and 46 (65.7\%) were female. Male to female ratio was 1:1.9. Mean age of patients put who underwent cholecystectomy in our

\begin{tabular}{|c|c|}
\hline \multicolumn{2}{|c|}{$\begin{array}{l}\text { Table-I: Complications after the laparoscopic } \\
\text { management of empyema gall bladder in the study } \\
(n=70) \text {. }\end{array}$} \\
\hline Complications & n (\%) \\
\hline Persistent post-operative pain & $02(2.8)$ \\
\hline Bile duct perforation and leakage & $06(8.5)$ \\
\hline Spilled gall stones & $03(4.3)$ \\
\hline Wound discharge or infection & $05(7.1)$ \\
\hline Bleeding & $03(4.3)$ \\
\hline Hospital stay for more than a week & $04(5.7)$ \\
\hline Duodenal perforation & $01(1.4)$ \\
\hline Others & $01(1.4)$ \\
\hline
\end{tabular}

study was $42.43 \pm 3.161$ years. Mean duration of hospital stay after the surgery was $5.23 \pm 2.481$ days. Bile leakage $6(8.5 \%)$ and perforation was the commonest complication among the target population followed by 
surgical site infection 5 (7.1\%). Duodenal perforation 1 $(1.4 \%)$ was least reported (table-I). Other characteristics of the patients have been summarized in table-II along with the application of chi-square which shows that high values of $C$ reactive protein and comorbid illnesses had significant association with presence of complications ( $p$-value $<0.05)$. With binary logistic regression we found that there are higher odds of complications in patients undergoing cholecystectomy who have high CRP and co-morbidties as time of admission (table-III).

Table-II: Various socio-demographic characteristics and the presence of post-operative complications.

\begin{tabular}{|c|c|c|c|}
\hline $\begin{array}{l}\text { Socio Demo- } \\
\text { graphic } \\
\text { Factors } \\
\text { Total }\end{array}$ & $\begin{array}{c}\text { Absence of } \\
\text { Complications } \\
n(\%) \\
46(65.7)\end{array}$ & $\begin{array}{c}\text { Presence of } \\
\text { Complications } \\
\text { n (\%) } \\
24(34.3)\end{array}$ & $\begin{array}{c}p- \\
\text { value }\end{array}$ \\
\hline \multicolumn{4}{|l|}{ Age } \\
\hline $\begin{array}{l}\geq 30 \text { year } \\
30-65\end{array}$ & $\begin{array}{l}17(36.9) \\
29(63.1)\end{array}$ & $\begin{array}{l}12(50) \\
12(50)\end{array}$ & 0.294 \\
\hline \multicolumn{4}{|l|}{ Gender } \\
\hline $\begin{array}{l}\text { Male } \\
\text { Female }\end{array}$ & $\begin{array}{l}17(36.9) \\
29(63.1)\end{array}$ & $\begin{array}{c}7(29.2) \\
17(70.8)\end{array}$ & 0.512 \\
\hline \multicolumn{4}{|c|}{ C-Reactive Protein } \\
\hline $\begin{array}{l}<5 \\
>5\end{array}$ & $\begin{array}{l}26(56.5) \\
20(43.5)\end{array}$ & $\begin{array}{c}2(83.3) \\
22(16.7)\end{array}$ & $<0.001$ \\
\hline \multicolumn{4}{|c|}{ Presence of Comorbidities } \\
\hline $\begin{array}{l}\text { No } \\
\text { Yes }\end{array}$ & $\begin{array}{c}42(91.3) \\
4(8.7) \\
\end{array}$ & $\begin{array}{l}12(50) \\
12(40)\end{array}$ & $<0.001$ \\
\hline \multicolumn{4}{|c|}{ Transfusion During Surgery } \\
\hline $\begin{array}{l}\text { No } \\
\text { Yes }\end{array}$ & $\begin{array}{l}36(78.2) \\
10(21.8)\end{array}$ & $\begin{array}{c}15(62.5) \\
9(37.5)\end{array}$ & 0.165 \\
\hline
\end{tabular}

Table-III: The correlated factors relating to presence of complications among the patients of empyema gall bladder undergoing laparoscopic management: the binary logistic regression analysis.

\begin{tabular}{|c|c|c|c|c|}
\hline \multirow[t]{2}{*}{ 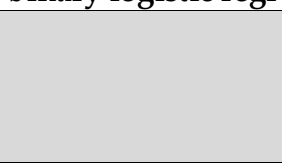 } & \multirow{2}{*}{$\begin{array}{c}p- \\
\text { value }\end{array}$} & \multirow{2}{*}{$\begin{array}{l}\text { Odds } \\
\text { Ratio }\end{array}$} & \multicolumn{2}{|c|}{$\begin{array}{c}\text { Confidence } \\
\text { Interval }\end{array}$} \\
\hline & & & $\begin{array}{l}\text { Lower } \\
\text { Limit }\end{array}$ & $\begin{array}{l}\text { Upper } \\
\text { Limit }\end{array}$ \\
\hline \multicolumn{5}{|l|}{ Age } \\
\hline Ref was $\geq 30$ years & 0.273 & 0.467 & 0.119 & 1.823 \\
\hline \multicolumn{5}{|c|}{ Per operative Transfusion } \\
\hline $\begin{array}{l}\text { Ref was no per } \\
\text { operative } \\
\text { transfusion }\end{array}$ & 0.105 & 0.228 & 0.038 & 1.361 \\
\hline \multicolumn{5}{|l|}{ Gender } \\
\hline Ref. was Male & 0.922 & 1.076 & 0.250 & 4.623 \\
\hline \multicolumn{5}{|l|}{ C Reactive Protein } \\
\hline Ref. was $<5$ & 0.001 & 25.070 & 3.796 & 165.580 \\
\hline \multicolumn{5}{|l|}{ Comorbidity } \\
\hline $\begin{array}{l}\text { Ref. was no } \\
\text { comorbidity }\end{array}$ & 0.003 & 17.709 & 2.583 & 121.422 \\
\hline
\end{tabular}

\section{DISCUSSION}

Conventional open surgery has been replaced by the laparoscopic method for most of the abdominal surgery and gynecological procedures ${ }^{16}$. Many centers of the world have evaluated this method and proved safety and efficacy in various surgeries of abdominal region ${ }^{17,18}$. Trained professionals for this job and cost related issues have been a problem linked with this procedure in a third world country like ours ${ }^{10}$. Their should be incorporation of all the expenses which a patient pose on the system in order to evaluate a treatment ${ }^{18}$. Both the entitled and private patients have been affected by the cost related problems as entitled patients pose burden on government for the charges and private patients have to do all from their own pocket. This matter is of great concern for the military set up like ours where number of disability days and patient not reaching the formation in time and joining the tough duties is of utmost importance. Therefore we planned this study. Evaluating the cost was a complex phenomenon involving a lot of parameters so was not included in the scope of study. The only objective of this study was to look for the various factors involved during safe laparoscopic cholecystectomy in cases of empyema gall bladder operated at Pak Emirates Military Hospital Rawalpindi.

Seventy patients of empyema of gall bladder participated in the analysis in the given study time. Though it was not a randomized control trial and laparoscopic method was not compared with open method; still it emerged as a safe procedure and most of the complications which patients faced were of minor nature. Around twenty four patients experienced one or more complications but that included very minor complications as well. Bile leakage and perforation $6(8.5 \%)$ was one of the serious complications but only six patients suffered from this. Infection was the second most common complication among our patients and that depends upon multiple factors in addition to the surgical modality used. Local and foreign studies done in 2017 and 2018 on similar patients have shown results in accordance with the results of our study and showed around 6\% had bile leakage after the surgery ${ }^{9,10}$. A randomized control trial with control of confounding factors may throw more light on safety of laparoscopic procedure in our set up.

Most of our patients were females 46 (65.7\%). Alarmingly high number of females highlights that the diseases of hepatobiliary region have been more common in females as compared to males. Gender was not 
associated with presence or absence of complications so had no link with safety of the procedure and we cannot hypothesize that laparoscopy has been safe in one gender and not in other in cases of empyema gall bladder. These results have been seen in the studies done previously as well in 2013 and 2017 where more than half of study population were females 8,11 .

Complication which was faced by most of the patients was bile leakage and perforation. Surgical site infection $5(7.1 \%)$ was second on the list. Similar findings have been reported in the studies done in other set ups in 2017 involving similar patients were SSI was in around $6 \%$ patients ${ }^{11,15}$. This finding accounts for the recommendation of planning of these types of studies in other centers as well. Laparoscopic surgeries are on a rise in our setup so exact knowledge of the complications linked to this procedure should be known by the treating surgeons in order to communicate effectively with the patients. As this method is different from the conventional open method so the type of complications linked to it would also be different. Therefore generalizing the results of western studies would not work for our population.

Presence of comorbidities emerged as strong predictor of presence of complications in our target population. Medical illnesses like DM or HTN etc can make the patient immuno-compromised and increase the chances of infection or other untoward effects after the surgical management. Treatment options used for comorbidities may also interact with the agents applied in the course of surgical management. It has been documented in the past as well in 2018 that patients with chronic medical illnesses are at a clear disadvantage of developing post-surgical complications especially wound infections by odd of more than $2^{14,15}$. Therefore it can be concluded that absence of comorbidities was linked with more safety of the procedure under study.

Raised CRP was another factor linked directly with presence of complications in our study. Previous studies in 2016 have produced similar results ${ }^{6}$. Higher CRP has higher complications rate.

Along with the strengths of the study in revealing the factors linked with outcome of laparoscopic management of empyema gall bladder, this study had few limitations as well. Socio-cultural and health related factors which can put an impact on the post-surgical recovery were not taken into account e.g socioeconomic status, nutrition status, caregiving options. A comparison was not made with the open method that laparoscopic method is useful in real sense in hands of local surgeons or it is causing more adverse effects as compared to conventional mode of surgery. Studies should be done in future incorporating overall cost and disability days due to complications by randomizing the patients can generate more generalizable results.

\section{CONCLUSION}

Limited number of patients faced the complications during or after the surgery. Patients with comorbid medical illnesses and high $C$ reactive protein before surgery should be screened with caution for the presence of complications after the surgery.

\section{CONFLICT OF INTEREST}

This study has no conflict of interest to be declared by any author.

\section{REFERENCES}

1. Vitale A, Lai Q. New trends and perspectives in hepatobiliary surgery: preface. Transl Gastroenterol Hepatol 2018; 3(1): 99-01.

2. Artifon EL, Loureiro JF, Baron TH, Fernandes K, Kahaleh M, Marson FP. Surgery or EUS-guided choledochoduodenostomy for malignant distal biliary obstruction after ERCP failure. Endosc Ultrasound 2015; 4(3): 235-43.

3. Hong KS, Noh KT, Min SK, Lee HK. Selection of surgical treatment types for intrahepatic duct stones. Korean J Hepatobiliary Pancreat Surg 2011; 15(3): 139-45.

4. Mehta V, Yarmish G, Greenstein J, Hahn B. Gallbladder Empyema. J Emerg Med 2016; 50(6): 893-94.

5. Khan ML, Abbassi MR, Jawed M, Shaikh U. Male gender and sonographic gall bladder wall thickness: important predictable factors for empyema and gangrene in acute cholecystitis. J Pak Med Assoc 2014; 64(2): 159-62.

6. Radunovic M, Lazovic R, Popovic N, Magdelinic M, Bulajic M, Radunovic L, et al. Complications of laparoscopic cholecystectomy: our experience from a retrospective analysis. Open Access Maced J Med Sci 2016; 4(4): 641-46.

7. Afzal M, Rehman S, Butt MQ. complications of laparoscopic cholecystectomy: an analysis of 400 consecutive cases. Pak Armed Forces Med J 2014; 64(4), 546-50.

8. Malik A, Laghari AA. Laparoscopic cholecystectomy in empyema of gall bladder: An experience at Liaquat University Hospital, Jamshoro, Pakistan. J Minim Access Surg 2007; 3(2): 52-56.

9. Hanif MS, Chaudry IA, Abbasi SA, Hasnain MR. Laparoscopic cholecystectomy for empyema gall bladder. Pak Armed Forces Med J 2017; 67 (3): 376-80.

10. Palaz Alı O, Ibis AC, Gurtekin B. Financial Aspects of Bile Duct Injuries. Med Sci Monit 2017; 23(1): 5264-70.

11. Altuntas YE, Oncel M, Haksal M, Kement M, Gundogdu E, Aksakal N, et al. Gallbladder perforation during elective laparoscopic cholecystectomy: Incidence, risk factors, and outcomes. North Clin Istanb 2018; 5(1): 47-53.

12. Taki-Eldin A, Badawy AE. Outcome of laparoscopic cholecystectomy in patients with gallstone disease at a secondary level care hospital. Arq Bras Cir Dig 2018; 31(1): e1347-50.

13. Akhtar A, Bukhari MM, Tariq U, Sheikh AB, Siddiqui FS, Sohail MS, et al. Spilled Gallstones Silent for a Decade: A Case Report and Review of Literature. Cureus 2018; 10(7): e2921-29.

14. Lee SI, Na BG, Yoo YS, Mun SP, Choi NK. Clinical outcome for laparoscopic cholecystectomy in extremely elderly patients. Ann Surg Treat Res 2015; 88(3): 145-51. 
15. Ahmed N, Hassan MU, Tahira M. Intra-operative predictors of difficult cholecystectomy and conversion to open cholecystectomy - a new scoring system. Pak J Med Sci 2018; 34(1): 62-66.

16. Lewis TL, Furness HN, Miller GW, Parsons N, Seers K, Underwoodet $\mathrm{M}$, et al. Adoption of a novel surgical innovation into clinical practice: protocol for a qualitative systematic review examining surgeon views. BMJ Open 2018; 8(4): e020486-90.
17. Kawiński A, Dziki Ł, Trzciński R, Dziki A, Mik M. Is there still a place for open surgery in the treatment strategy of rectal cancer?. Prz Gastroenterol 2018; 13(4): 289-92.

18. Kerwat D, Zargaran A, Bharamgoudar R, Arif N, Bello G. Early laparoscopic cholecystectomy is more cost-effective than delayed laparoscopic cholecystectomy in the treat-ment of acute cholecystitis. Clinicoecon Outcomes Res 2018; 10(1): 119-25. 